\title{
Research on Container Intermodal Transport Route Optimization under the Carbon Emission Trading
}

\author{
Li Jialing \\ School of Management \\ Guangxi University of Science \& Technology \\ Liuzhou, China \\ E-mail: 596145246@qq.com
}

\author{
Liao Zhigao * \\ School of Management \\ Guangxi University of Science \& Technology \\ Liuzhou, China \\ E-mail: liaozhigao@126.com \\ * Corresponding Author
}

\begin{abstract}
The reasonable selection of container intermodal path is of great significance to the reduction of the transportation cost. With the implementation of carbon trading market, analysis the impact of carbon emission trading on the selection of the intermodal path and the total cost is conductive to provide constructive advice. A path optimization model aiming at minimizing the total cost was established under the current initial quota mechanism of carbon trading market. Then, the CPLEX software was used to solve the model. Finally, a preliminary discussion was presented. The results show that discriminative path exist in different scenarios; the total cost and carbon emissions of path optimization model with the carbon cost are far less than that of path optimization model without carbon cost. Arranging the production rationally, selling out the extra carbon quota and converting the carbon cost into the additional profit, to some extent, the total cost can be decreased under the different carbon quota and prices.
\end{abstract}

Keywords-Integrated Transpotation; Carbon Trading Market; Intermodal Transport; Route Optimization; LowCarbon

\section{INTRODUCTION}

According to the data from the national development and reform commission, the total national social logistics have grown to 17.73 billion yuan, total social logistics cost ratio of GDP $18 \%$ in 2012. With the development of market economy, logistics industry has grown as a leading industry to guide production and promote consumption. However, the logistics industry is also a high energy consumption and high pollution industry, which has been a more and more serious negative impact on the ecological environment, such as exhaust gas pollution, noise pollution and carbon emissions, etc. The stern report shows logistics transportation accounts for $14 \%$ of global greenhouse gas emissions. And China's logistics industry fuel consumption accounts for about $34 \%$ of the total consumption, carbon dioxide emissions $18.9 \%$, and energy costs accounted for $40 \%$ of logistics enterprises and even the $80 \%$ [1]. Therefore development of convenient and efficient, green low carbon transport has become the inevitable trend of logistics industry; And intermodal transport, with its huge capacity, lower transport costs and relatively less pollution emissions and other unique advantages, has become a prior transportation mode of all countries in the world, which is one of the 12 key projects among the medium and longterm development of logistics industry planning (20142020) (hereinafter referred to as the "plan") issued by the State Council on September 12, 2014

The existing research on path optimization of intermodal transport is mostly based on the traveling salesman model (TSP) and the vehicle routing problem (VRP) model. Most early research concentrated on the linear programming model established by minimizing the total cost of the target [2-5]. For example, Chun-Hsiung Liao et al. (2009) [6] calculated the carbon dioxide emissions of the trucks and compare it with that of the truck-rail. The result shows that it will effectively reduce carbon dioxide emissions when highway-railway intermodal transport replace the long-haul truck. M. Soysaln et al. (2014) [7] took minimization carbon emissions as one of the objective functions but transformed the objective function into constraints to solve it. Gloria R. Gerilla et al. (2005) [8] Analyzed and compared intermodal transport emission issue from the manufacturer to the middlemen on the basis of the theory of life cycle analysis; and results show that the greenhouse gas emission of the highway transportation is most serious among other transportation modes. Based on multiobjective optimization model, Nam Seok Kim et al. (2009) [9] analyzed the relationship between logistics cost and carbon emissions and found that there is a negative correlation between logistics cost and carbon dioxide emissions, it is suggested to moderately balance the relationship between them.

Though the above literatures consider the environmental factors, it is of less actual significance to only take carbon emissions as the objective function or constraint. As the proposition of gradually establishing a carbon emissions trading market by the "twelfth five-year" plan and the beginning of the pilot work on carbon emissions trading in seven provinces and cities such as Beijing, Tianjin, the research on routes optimization with carbon trading will be more realistic and important; however, most of the existing articles about carbon trading focus on the traditional VRP problems [10]-[12]. Few literatures combined with carbon emission trading study the intermodal transport route optimization. 
Above all, this paper aims at studying problem of intermodal transport route choice from the low-carbon prospective. Different from the past will only carbon emissions as the target or constraint and innovation points of this paper is to consider the carbon cost, combined with the background introduction of carbon trading market price, converts carbon emissions to the carbon costs. This paper is divided into four parts: the first part is introduction, introduces relevant background and literature review; The second part of the carbon emission trading intermodal transport path optimization model is set up; The third part introduces the algorithm; The fourth part USES case to verify this solution model; The fifth part is the full text of the summary and outlook.

\section{MODEL FORMULATION}

\section{A. Problem Description and Assumptions}

Assume a batch of goods starts from the originating node $\mathrm{O}$ to the destination $\mathrm{D}$ passing several cities with three modes of transportation. Thus this paper aims to (1) analysis the impact of the changes of the carbon trading price and carbon quota on the total cost of the intermodal transport under different scenarios; (2) choose the appropriate route and transport mode, make the goods transport to the destination with the lowest total cost. In this article, we make the following assumptions: (1) The buying or selling carbon quotas is a one-time activity; and (2) the carbon trading buying and selling prices are assumed to be a constant to facilitate the later concrete analysis, because carbon price fluctuates dramatically affected by the relation between supply and demand of the carbon market.

\section{B. Indices and Parameters}

$\mathrm{c}_{i j}^{m}$ : Unit cost from node $i$ to node $j$ with the mode of the transportation $m$

$c_{i}^{m n}$ : Unit transship cost in node $i$ t from the mode of the transportation $m$ to $n$

$t_{i j}^{m}:$ Transit time from node $i$ to node $j$ with the mode of the transportation $m$

$t_{i}^{m n}$ : Transshipping time in node $i \mathrm{t}$ from the mode of the transportation $m$ to $n$

$e_{i j}^{m}:$ Unit distance carbon dioxide emissions from node to node $\mathrm{j}$ with the mode of transportation $m$

$e_{i}^{m n}$ : Unitized cargo carbon dioxide emissions at node $\mathrm{I}$ from mode of transportation $\mathrm{m}$ to mode of transportation $n$

$d_{\mathrm{ij}}^{m}$ : Distance from node $i$ to $j$ with the mode of transportation $m$

$c a p_{i j}^{\mathrm{m}}$ : Transportation capacity limitation from node $i$ to node with the mode of transportation $m$ $q$ : Freight volume

$T$ : The freight total time agreed in the contract

$P$ : Carbon price

$\alpha$ : Auction ratio (the proportion of auctioned carbon quota in the total quota)

$L$ : Initial carbon quotas

$W$ : Total carbon dioxide emission

$N$ : Delivery times

$x_{i j}^{m}=\left\{\begin{array}{l}1, \text { excting route from } i \text { to } j \text { with } m \\ 0, \text { otherwise }\end{array}\right.$

$y_{i}^{m n}=\left\{\begin{array}{l}1, \text { converting mode from } m \text { to } n \text { at } i \\ 0, \text { otherwise }\end{array}\right.$

\section{Objective function and constraints}

According to the distribution of carbon quotas of the carbon emission trading, we introduce the auction ratio into the objective function (1): $\alpha \cdot P_{1} \cdot L+P_{2} \cdot(N \cdot W-L)$ means carbon emission cost; formula (2) is the total carbon emissions in the process of transportation (transport carbon emission and the transship carbon emission). formula (3) and (4) are special situations, respectively: when $\alpha=0$ and $N \cdot W=L$, formula (1) converts to formula (3) with the economic cost minimization objective function (The initial carbon quotas of the enterprise are free distribution, and carbon quotas rightly equally to the actual carbon emissions); when $\alpha=0$ and $N \cdot W \neq L$, The objective function is formula (4):

$$
\begin{aligned}
& \min C=N \cdot\left[\sum_{i, j \in V} \sum_{m, n \in M}\left(c_{i j}^{m} x_{i j}^{m} q d_{i j}^{m}+y_{i}^{m n} c_{i}^{m n} q\right)\right]+\alpha \cdot L \cdot P_{1}+P_{2} \cdot(N \cdot W-L) \\
& W=\sum_{i, j \in V} \sum_{m, n \in M} e_{i j}^{m} x_{i j}^{m} q d_{i j}^{m}+\sum_{i, j \in V} \sum_{m, n \in M} e_{i}^{m n} y_{i}^{m n} q \\
& \min C_{0}=N \cdot\left[\sum_{i, j \in V} \sum_{m, n \in M}\left(c_{i j}^{m} x_{i j}^{m} q d_{i j}^{m}+y_{i}^{m n} c_{i}^{m n} q\right)\right] \\
& \min C^{*}=N \cdot\left[\sum_{i, j \in V} \sum_{m, n \in M}\left(c_{i j}^{m} x_{i j}^{m} q d_{i j}^{m}+y_{i}^{m n} c_{i}^{m n} q\right)\right]+P_{2} \cdot(N \cdot W-L)
\end{aligned}
$$

s.t.

$$
\begin{gathered}
\sum_{m \in M} x_{i j}^{m}-\sum_{m \in M} x_{j i}^{m}=\left\{\begin{array}{l}
1, \forall i \in \mathrm{S} \\
-1, \forall i \in D \\
0, \forall i \in \mathrm{V}
\end{array}\right. \\
\sum_{m \in M} x_{i j}^{m} \leq 1 \quad \forall i, j \in V \\
\sum_{m \in \mathrm{M}} \sum_{n \in \mathrm{M}} y_{i}^{m n} \leq 1 \quad \forall i \in V \\
\sum_{i, j \in V} \sum_{m \in M} x_{i j}^{m} t_{i j}^{m}+\sum_{i \in V} \sum_{m, n \in M} y_{i}^{m n} t_{i}^{m n} \leq T \\
q x_{i j}^{m} \leq c a p_{i j}^{m} x_{i j}^{m} \quad \forall i \in V, \forall m, n \in M
\end{gathered}
$$




$$
\begin{array}{cc}
x_{k, i}^{m}+x_{i, j}^{n} \geq 2 y_{i}^{m n} & \forall k, i, j \in V, \forall m, n \in M \\
x_{k, i}^{m}+x_{i, j}^{n}-1 \leq 2 y_{i}^{m n} & \forall k, i, j \in V, \forall m, n \in M(11) \\
x_{i j}^{m}, y_{i}^{m n} \in\{1,0\} & \forall i \in V, \forall m, n \in M
\end{array}
$$

Constraint (5) means the integrity of the transportation channels (the uniqueness of the in and out channel of each node); (6) if it is allowed to exist transport path between two nodes, then only one path with one mode of transportation; (7) if one node has to transform its mode of transportation, then only from one mode of transportation to another one mode of transportation; (8) the total transportation time must be within the stipulated time; (9) is the limitation of the capacity from node $i$ to node $j$ with the mode of the transportation $m$; (10) and (11) ensure the continuity during the transportation; (12) means the $x_{i j}^{m}$ and $y_{i}^{m n}$ are binary variable.

\section{NUMERIC ANALYSIS}

As shown in Figure 1: We assumes that a batch of goods starting from node $\mathrm{S}$ to the destination $\mathrm{D}$ through 4 nodes. There are 3 kind of mode of transportation: highway, railway and waterway. The relevant simulated data in the transportation network are given by the Tab. 1 (distance of the 6 nodes, unit transportation costs, unit transportation time, et al.). Table 2 is relevant simulated transship data (switching cost, time per unit and $\mathrm{CO} 2$ emissions from different transport modes) [13]. The carbon trading price $P(¥ / \mathrm{t}): 20,31$ and 53, which are the minimum, average and maximum of the 5 pilots (Beijing, Tianjin, Shanghai, Guangzhou, Chongqing) of carbon trading market in China, respectively. Here, $\mathrm{N}=24$, assuming that there is 24 transportation activities within a year. The software CPLEX is used to solve the model.

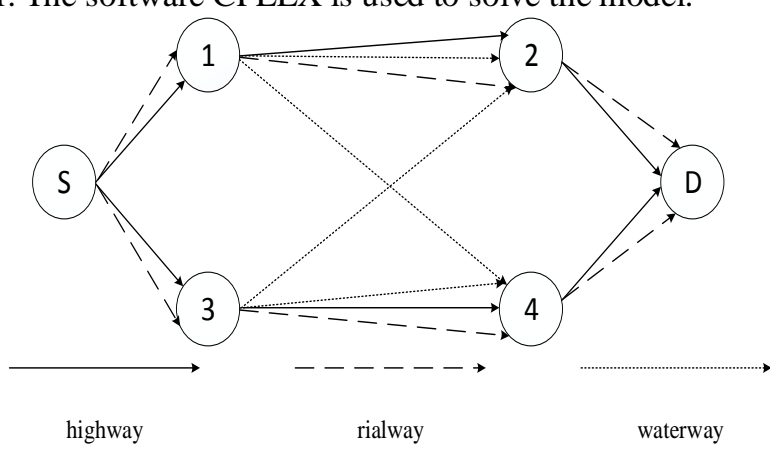

Figure.1 Intermodal Transportation Case Diagram

TABLE I. DATA FOR CONTAINER INTERMODAL TRANSPORT NETWORK CASE

\begin{tabular}{ccccccc}
\hline \multirow{2}{*}{ Node } & \multicolumn{2}{c}{ Distance(km) } & \multicolumn{3}{c}{$\begin{array}{c}\text { Unit of Distance } \\
\text { Transportation Cost } \\
\text { (¥/tkm) }\end{array}$} \\
\cline { 2 - 7 } & Road & rail & water & Road & rail & water \\
\hline $\mathrm{S} \rightarrow 1$ & 300 & 500 & - & 3 & 2 & - \\
$\mathrm{S} \rightarrow 3$ & 290 & 340 & - & 3 & 2 & - \\
$1 \rightarrow 2$ & 250 & 370 & 180 & 3 & 2 & 1 \\
$1 \rightarrow 4$ & - & - & 190 & - & - & 1 \\
\hline
\end{tabular}

\begin{tabular}{ccccccc}
\hline $2 \rightarrow \mathrm{D}$ & 180 & 260 & - & 3 & 2 & - \\
$3 \rightarrow 2$ & - & - & 200 & - & - & 1 \\
$3 \rightarrow 4$ & 140 & 220 & 130 & 3 & 2 & 1 \\
$4 \rightarrow \mathrm{D}$ & 190 & 240 & - & 3 & 2 & - \\
\hline
\end{tabular}

TABLE II. SWITCHING COST/TIME PER UNIT AND $\mathrm{CO}_{2}$ EMISSIONS FACTORS OF DIFFERENT TRANSPORT MODES

\begin{tabular}{cccc}
\hline & Road & rail & water \\
\hline Road & $0 / 0$ & $3 / 2$ & $2 / 1$ \\
Rail & $3 / 2$ & $0 / 0$ & $2 / 2$ \\
water & $2 / 1 /$ & $2 / 2$ & $0 / 0$ \\
Carbon & 0.04795 & 0.00841 & 0.01733 \\
emission & & & \\
\hline
\end{tabular}

\section{DISSCUSSION}

\section{A. The Impact of the Carbon Emission Trading on the Route Selection}

The two best routes are shown in table 3. Scenario1: When enterprises only consider economic cost (there isn't carbon dioxide emission constraint ), the optimal transport routes is $\mathrm{S}$ road 3 water 2 rail $\mathrm{D}$; total carbon dioxide emission and cost are 571 488, 41900 000,respectivel. Scenario 2: under the carbon trading market (with free initial carbon quota $\mathrm{L}=30000 ; 40000$ and $\mathrm{P}=31$ ), the optimal transport routes is $\mathrm{S}$ rail 1 water 2 rail $\mathrm{D}$. because of the constraint of the carbon emission trading, the carbon dioxide emission dramatic declines to 318312 .

When $L=30000 \leq N \cdot W(N=24)$, actual carbon quotas exceeds initial carbon quotas, enterprises need to purchase carbon credits. carbon dioxide emission cost as punishment cost added to the total cost. Thus the total cost under Scenario 2 is significantly higher than that of Scenario 1. when $L=40 \quad 000 \geq N \cdot W(N=24)$, the enterprise actual carbon quotas is less than initial carbon quotas. After the enterprise sells surplus carbon quotas, carbon cost is converted into additional profits, the total costs is down to 38840000 .

\begin{tabular}{|c|c|c|c|}
\hline scenario & Best route & $\begin{array}{c}\text { Carbon } \\
\text { dioxide } \\
\text { emission }\end{array}$ & $\begin{array}{l}\text { Total cost } \\
\left(\begin{array}{l}L=30000 \\
L=40000)\end{array}\right.\end{array}$ \\
\hline 1 & $\mathrm{~S}$ road 3 water 2 rail $\mathrm{D}$ & 571488 & 41900000 \\
\hline 2 & $\mathrm{~S} \underline{\text { rail }} 1$ water 2 rail $\mathrm{D}$ & 318312 & $\begin{array}{l}43508000 \\
38840000\end{array}$ \\
\hline
\end{tabular}

TABLE III. INTERMODAL TRANSPORTATION PLANS AND TOTAL COST UNDER DIFFERENT SCENARIOS

\section{B. The Impact of the Carbon Emission Trading on the} Cost

a) $\alpha=0$ and $N \cdot W=L$, formula (1) is converted into(3). the total cost is composed of transportation costs and switching costs without the effect of the Transportation costs and switching costs. Here we mainly focus on formula (4)) $(N \cdot W \neq L)$ :

$N \cdot W-L>0$, actual carbon quotas exceed initial carbon quotas, enterprises need to purchase carbon credits 
in carbon trading market. Carbon dioxide emission cost as punishment cost added to the total cost. The fewer the carbon quotas, the higher the total cost will be. And under the same carbon quotas, the higher the price of carbon trading is, the more the enterprise spends to buy carbon quotas. When $N \cdot W-L<0$, the enterprise actual carbon quotas is less than initial carbon quotas. The carbon cost is negative, which, as a part of profit, plays a more and more important role offsetting total cost. Therefore, the more carbon quotas, the less the total cost would become; And under the same carbon quotas, the higher the carbon price becomes, the more income of selling carbon and the less total cost will be.

b) $\alpha \neq 0$, enterprise needs to purchase $\alpha$ percent of the initial carbon quotas with the pirce. The remainder $(L-\alpha \cdot L)$ is free distribution.

When $\mathrm{NW}<\mathrm{L}$, if auction ratio $\alpha<\frac{P_{2}\left(L-N^{*} W\right)}{P_{1}^{*} L}$, thus $P_{2} \cdot(N \cdot W-L)>\alpha P_{1} L$. When the auction $\alpha$ and auction prices $P_{1}$ remain unchanged, with the increasing of the $P_{2}$ (carbon price for buying) and $N \cdot W-L$ (carbon quota balance), the offset of the carbon cost becomes greater, and total cost will reduce; When $\mathrm{P}_{2}$ and remain unchanged, total cost raises with the increase of the $\alpha$ and auction prices P1 ; if $\alpha>\frac{P_{2}\left(L-N^{*} W\right)}{P_{1}^{*} L}$, the total cost raises as $\alpha, \mathrm{P}_{2}$ and $\mathrm{L}$ rise.

TABLE IV. THE CHANGES OF THE TOTAL COST AND PURCHASE QUANTITY OF CARBON QUOTA UNDER DIFFERENT CARBON TRADING PRICE AND QUANTITY OF CARBON QUOTA

\begin{tabular}{lllll}
\hline $\mathbf{L}$ & $\mathbf{P 2 = 2 0}$ & $\mathbf{P 2 = 3 1}$ & $\mathbf{P 2 = 5 3}$ & $\begin{array}{c}\text { Carbon } \\
\text { buying/sel } \\
\text { ling }\end{array}$ \\
\hline 100000 & 47307000 & 49708000 & 54511000 & $218312^{+}$ \\
200000 & 45307000 & 46608000 & 49211000 & $118312^{+}$ \\
300000 & 43307000 & 43508000 & 43911000 & $18312^{+}$ \\
318312 & 41940000 & 41940000 & 41940000 & 0 \\
400000 & 41307000 & 40408000 & 38611000 & $81688^{-}$ \\
500000 & 39307000 & 37308000 & 33311000 & $181688^{-}$ \\
600000 & 37307000 & 34208000 & 28011000 & $281688^{-}$ \\
700000 & 35307000 & 31108000 & 22711000 & $381688^{-}$ \\
800000 & 33307000 & 28008000 & 17411000 & $481688^{-}$ \\
900000 & 31307000 & 24908000 & 12110000 & $581688^{-}$ \\
\hline
\end{tabular}

\section{CONCLUSIONS}

This paper makes a study of intermodal transport route optimization problems combined with the carbon emission trading, compares two different models with objective function of the traditional economic cost minimization and carbon emission cost, and analyzes the impact of the $\alpha$ (auction ratio), $\mathrm{P}$ (carbon price) and $L$ (carbon quota). And it is found that as long as enterprises make reasonable arrangement of the production, and do a good job in energy conservation, emissions reduction and decrease carbon dioxide emission, the sold remainder carbon quotas can convert carbon cost into the parts of the enterprise profits to reduce the total cost. In the future, more researches can focus on factors of the carbon price, or consider other carbon policies, such as carbon tax, carbon offset et al.

\section{ACKNOWLEDGMENT}

This paper was supported by 1) the outstanding young backbone teachers' training program in higher education institutions of Guangxi, China; 2) Guangxi Philosophy and Social Science Fund (The Grant No. 13BGL009) and 3) The teaching reform project in higher education of Guangxi (No. 2012JGA178).

\section{REFERENCES}

[1] Stern N. Stern review: The economics of climate change. HM Treasury, London, 2006.

[2] Crainic, T. G. "Service network design in freight transportation", European Journal of Operational Research 122.2 (2000): 272-288.

[3] Forkenbrock, D. J. "External costs of intercity truck freight transportation", Transportation Research Part A: Policy and Practice 33.7-8 (1999): 505-526.

[4] Forkenbrock, D. J. "Comparison of external costs of rail and truck freight transportation", Transportation Research Part A: Policy and Practice 35.4 (2001):321-337.

[5] Zeng yong-chang, wang yong, lai zhi-zhu. Research on model and algorithm of multimodal transportation with time windows. Industrial engineering journal 12.2 (2009): 24-29.

[6] Chun-Hsiung Liao, Po-Hsing Tseng, Chin-Shan Lu. "Comparing carbon dioxide emissions of trucking and intermodal container transport in Taiwan”, Transportation Research Part D 14.7 (2009): 493-493.

[7] M. Soysaln, J.M. Bloemhof-Ruwaard, J.G.A.J. van der Vorst. "Modeling food logistics networks with emission considerations: The case of an international beef supply chain." Int. J. Production Economics 152(2014): 57-70.

[8] Gloria R.Gerilla, Kardi Teknomo. "Environmental Assessment of International Transportation of Products" Journal of the Eastern Asia Society for Transportation Studies 6 (2005): 3167-3182.

[9] Nam Seok Kim, Milan Janic, Bert van Wee. "Trade-off Between Carbon Dioxide Emissions and Logistics Costs Based on Multiobjective Optimization." Transportation Research Record 2139 (2009): 107-116.

[10] LI J, ZHANG J H. Study on the effect of carbon emission trading mechanism on logistics distribution routing decisions ". Systems Engineering — Theory and Practice 34.7(2014): 1779-1788.

[11] YANG J, LU W. "A Location and Distribution Model with Hierarchical Capacities under Different Carbon Emission Policies." Chinese Journal of Management Science 22.5(2014): 51-60.

[12] Emrah Demir Tolga Bektas, Gilbert Laporte. "A review of recent research on green road freight transportation". European Journal of Operational Research 237(2014): 775-793.

[13] SHEN Z J, Yang B. "Considering Greenhouse Gas Emission in Operation Strategies of Container Logistics. Journal of Wuhan University of Technoloyg 34.5 (2012): 70-76.Bao JIANG, Jian Li, Xiaoying MAO. Container Poret Multimodal Transport in China from the View of Low Carbon [J]. The AsianJournal of Shipping and Logistics, 2012, 28(3): 321-344. 